\title{
La enseñanza de verbos frecuentes a partir de enfoques léxicos
}

Palabras clave: verbos frecuentes, verbos de apoyo, enfoques léxicos, colocaciones, enseñanza de vocabulario

\section{Introducción}

Desde la aparición de los primeros trabajos sobre enfoques léxicos, cuyos hallazgos fundamentales fueron aglutinados y ampliados por Lewis (1993, 1997, 2000), la investigación ha ido respaldando con rigor los principios que sustentan la aplicación de los planteamientos lexicalistas a la enseñanza de segundas lenguas, de tal modo que pueden ya citarse varias premisas plenamente consolidadas: 1) el léxico es primordial en la adquisición de una lengua, pues en él reside el significado y constituye la base para el desarrollo de las destrezas y habilidades comunicativas (Alderson, 2005; Tomasello, 2003); 2) un ítem léxico no es simplemente la unión de forma y significado, sino que consta de varios rasgos que conforman lo que puede denominarse profundidad léxica (Richards, 1976; Nation, 2001; Baralo, 2006): marcas de registro, restricciones combinatorias, relaciones morfológicas, conexiones semánticas, usos figurados, etc.; 3) el léxico de una lengua está formado por palabras y por unidades multipalabra o bloques léxicos más o menos estables (locuciones, marcadores discursivos, paremias, colocaciones, etc.) que constituyen una gran parte - aún no cuantificada con exactitud- del discurso nativo (Wray, 2002; Stengers, 2009); 4) el léxico más frecuente debe ser objeto prioritario de aprendizaje, pues abarca una gran parte del discurso nativo cotidiano (Nation, 2008); 5 ) el aprendizaje del léxico es más eficaz si se toma conciencia de las semejanzas y diferencias entre la L1 y la L2 (Swan, 
1997) y cuando exige elaboración o procesamiento profundo de la información léxica (Barcroft, 2012; Cheikh-Khamis Cases, 2016); 6) el aprendizaje de un ítem léxico es gradual (Leow, 2015): se advierte en el input, se procesa de manera profunda y se almacena en el lexicón por medio de redes (Nagini, 2008) y, por último, se recupera en la producción ${ }^{1}$.

En el ámbito de la enseñanza del español, estos preceptos son en general conocidos, pues son ya muchos los talleres, conferencias, publicaciones, tesis doctorales o trabajos de fin de estudios que los recogen, $y$, aunque de manera todavía tímida, comienzan a reflejarse en los materiales de enseñanza ${ }^{2}$. Pero una vez dado este paso de difusión general, tal vez es momento de aplicar estos principios a aspectos concretos de la realidad lingüística del español, para, poco a poco, ir construyendo una enseñanza integral de base lexicalista. En este trabajo tratamos de avanzar en esa dirección, y proponemos un tratamiento de los verbos frecuentes del español a partir de las directrices mencionadas.

\section{Los verbos frecuentes del español}

Debemos considerar los verbos frecuentes como un elemento clave del componente léxico por dos razones. La primera de ellas, ya señalada, tiene que ver con la importancia del vocabulario frecuente en los actos de comunicación nativa. Las unidades léxicas más frecuentes de una lengua están presentes en todos los registros y contextos lingüísticos orales y escritos (formal, informal, novelas, conversación, periódicos, textos académicos, etc.), por lo que se caracterizan también por su gran alcance y dispersión. Esto provoca que los aprendientes de una lengua extranjera tengan muchas oportunidades de encontrarlas en el discurso y de usarlas; según Nation (2008), las 2000 palabras más frecuentes constituyen en la mayoría de los textos el $80 \%$ de su vocabulario, y en la conversación diaria informal alcanzan hasta el $95 \%$. Afirma Nation que esta cantidad de palabras puede $\mathrm{cu}-$ brirse en un periodo de entre 3 y 5 años, aunque eso dependerá del número de horas de instrucción. En todo caso, debieran manejarse al completar el nivel $\mathrm{B} 1$, ya que, de acuerdo con las escalas del MCER para la gradación del conocimiento del vocabulario y para la capacidad de controlar ese conocimiento, un aprendiente de nivel B1 (2002: 109) «tiene suficiente vocabulario para expresarse con algún circunloquio sobre la mayoría de los temas

1 Para un tratamiento más detallado de estas premisas, véase Rufat y Jiménez Calderón (2019).

2 Véase un estado de la cuestión más profundo en Sánchez Rufat y Jiménez Calderón (2015). 
pertinentes para su vida diaria, como, por ejemplo, la familia, aficiones e intereses, trabajo, viajes y hechos de actualidad», lo que significa que se defiende de manera cómoda en la conversación cotidiana informal; en otras palabras, manejaría en torno al $95 \%$ del vocabulario de la conversación, caracterizado por las 2000 unidades léxicas más frecuentes. En el nivel B2, en cambio, el aprendiente «dispone de un amplio vocabulario sobre asuntos relativos a su especialidad» $\mathrm{y}$ «manifiesta un buen dominio del vocabulario elemental, pero todavía comete errores importantes cuando expresa pensamientos más complejos, o cuando aborda temas y situaciones poco frecuentes»; dicho de otro modo, se desenvuelve en la conversación cotidiana informal -por lo que tendría adquiridas las 2000 palabras más frecuentes-, pero va más allá en su conocimiento del léxico porque también maneja el vocabulario de ciertos ámbitos específicos.

Obviamente, no todo este vocabulario frecuente puede trabajarse en el aula. Parte de él se adquiere o se fija de manera implícita, por exposición, con lo que solo los ítems más complejos han de reservarse para la instrucción directa. En el caso de los verbos, los más frecuentes deberían ser, por lo tanto, objeto prioritario de aprendizaje explícito, y no solo por su alta rentabilidad, sino, efectivamente, por su gran complejidad. La segunda razón es que, de entre los elementos léxicos, el verbo constituye un área fundamental de la estructura de cualquier lengua, pues contiene concreciones argumentales que provocan que el significado de la oración se asimile al del verbo que la proyecta (Rufat, 2019: 13). Esta circunstancia lo convierte en una fuente de errores para los aprendientes especialmente significativa (Housen, 2002: 78), sobre todo si hablamos de verbos semántica y sintácticamente complejos.

Ambos aspectos, frecuencia y complejidad, están directamente relacionados, ya que la alta frecuencia de determinados verbos se explica precisamente por su capacidad para aparecer en contextos sintácticos muy diversos. En efecto, podría pensarse que, en tanto que el aprendiente está muy expuesto a los elementos más frecuentes en la lengua, estos deberían resultar más fáciles de aprender. Pero la variedad de posibilidades combinatorias que los verbos frecuentes ofrecen contribuye decisivamente a la dificultad de su manejo (Rufat, 2019). Con vistas a la explotación didáctica, recogemos aquí los 50 verbos más frecuentes del español según Davies y Davies (2018), que, atendiendo a lo anterior, deberían ser trabajados en los primeros niveles de aprendizaje: 


\begin{tabular}{|c|c|c|c|c|}
\hline 1) ser 07 & 11) saber 44 & 21) seguir 99 & 31) conocer 128 & 41) empezar 175 \\
\hline 2) haber 13 & 12) querer 58 & 22) quedar 100 & 32) tomar 133 & 42) buscar 179 \\
\hline 3) tener 19 & 13) pasar 68 & 23) Ilevar 101 & 33) sentir 136 & 43) existir 194 \\
\hline 4) estar 21 & 14) deber 71 & 24) encontrar 102 & 34) tratar 141 & 44) perder 195 \\
\hline 5) hacer 26 & 15) Ilegar 75 & 25) pensar 105 & 35) vivir 142 & 45) escribir 198 \\
\hline 6) decir 31 & 16) creer 83 & 26) volver 112 & 36) acercar 156 & 46) realizar 205 \\
\hline 7) poder 32 & 17) dejar 86 & 27) salir 114 & 37) esperar 157 & 47) entrar 207 \\
\hline 8) ir 33 & 18) parecer 89 & 28) venir 118 & 38) gustar 163 & 48) leer 209 \\
\hline 9) ver 38 & 19) hablar 90 & 29) Ilamar 122 & 39) contar 172 & 49) recordar 211 \\
\hline 10) dar 42 & 20) poner 91 & 30) mirar 125 & 40) trabajar 174 & 50) morir 212 \\
\hline
\end{tabular}

Tabla 1: verbos más frecuentes del español (a partir de Davies y Davies, 2018)

La cifra que aparece junto al verbo indica su posición absoluta en la lista de frecuencia; así, por ejemplo, ser es el verbo más frecuente y, al mismo tiempo, la séptima palabra más frecuente del español. Este repertorio debería ampliarse, al menos, hasta abarcar la lista completa de Davies y Davies, para luego distribuir los ítems por niveles. No obstante, conviene hacer algunas matizaciones. La primera es que, además de recoger todas las formas posibles del verbo, el lema también incluye cualquier otra palabra - si la hay- que coincida con alguna de esas formas, ya que las herramientas informáticas empleadas para obtener resultados de los corpus no distinguen, a priori, entre categorías gramaticales ni entre significados. Por ejemplo, en el caso de pasar, no se distinguirá entre la forma de la primera persona del presente del singular paso y el sustantivo paso, con lo que ambos ítems contarán como forma verbal; y en el caso de creer, no se distinguirá el cree de creer del de crear. Por otro lado, tampoco se distinguen las formas pronominales de las no pronominales, con lo que un lema como volver incluirá también las formas de volverse, a pesar de las diferencias entre ambos tipos. Con todo, el repertorio constituye hasta el momento el punto de partida más fiable a la hora de seleccionar los verbos con los que puede trabajarse.

Varios de estos verbos deben parte de su complejidad al hecho de que funcionan en ocasiones como verbos de apoyo, con lo que, en combinación con sustantivos, dan lugar a construcciones en las que el significado del verbo se difumina, hasta el punto de que se habla de verbos semánticamente vacíos que «conjugan» al nombre al que acompañan (Blanco Escoda, 2000: 99). Al respecto, cabe discutir sobre el verdadero alcance del significado de estos verbos, lo cual, como se verá más abajo, tiene implicaciones directas en el tratamiento en el aula. Así, se ha debatido si este tipo de verbos presenta un solo significado muy amplio o más de un significado. Aunque hay especialistas que hablan 
de polisemia (Tsutahara, 2018), muchos estudios han tratado de relacionar semánticamente todos los usos de un mismo verbo frecuente: Gumiel Molina (2008) sistematiza las posibilidades combinatorias de ser y estar con sus distintos predicados a partir del significado de estos; Sanromán Vilas (2014) cruza las combinatorias de dar y bacer para explorar las relaciones léxico-semánticas de ambos verbos; Sánchez Rufat (2015) relaciona todas las combinaciones posibles de dar desde una perspectiva semántica común; Urbaniak (2016) se ocupa de diferentes usos del verbo hacer; Conde Noguerol (2018a, 2018b) clasifica gran parte de la combinatoria de los verbos de cambio ponerse y bacerse; etc. Estudios como estos resultan imprescindibles para el desarrollo de aplicaciones didácticas, pues solo es posible sistematizar la enseñanza de un verbo frecuente si cuenta con una caracterización teórica sólida.

\section{El concepto de colocación en sentido restringido}

La enseñanza de verbos frecuentes apunta directamente al aspecto de las combinaciones léxicas. Decíamos más arriba que gran parte del léxico de una lengua la constituyen los bloques léxicos más o menos estables o lengua formulaica, es decir, las cadenas de palabras que se almacenan y se recuperan en el lexicón de manera holística y que no son, entonces, combinaciones o enunciados construidos palabra por palabra a partir del conocimiento que se tiene de la gramática. Aún no sabemos exactamente qué porcentaje representa esta lengua formulaica en el discurso nativo, aunque suele cifrarse en torno a la mitad (Erman y Warren, 2000); sí se ha demostrado que, en el caso del español, es al menos tan importante como en el inglés (Boers y Stengers, 2008). Dadas tanto la presencia como la rentabilidad y utilidad de estos bloques léxicos en el aprendizaje de lenguas, pues facilitan los intercambios comunicativos básicos y repetitivos y permiten desenvolverse en conversaciones sencillas con mayor fluidez, el próximo paso en este sentido debería consistir en elaborar un repertorio de las expresiones formulaicas más frecuentes del español, lo cual no resultará fácil, pues será necesario diseñar una herramienta informática que las identifique a partir de los corpus disponibles 3 . Una vez hecho eso, habrá que clasificarlas y buscar las mejores aplicaciones para la enseñanza de cada uno de los tipos ${ }^{4}$. Mientras esto llega, conviene seguir desarrollando propuestas para la enseñanza de determinadas combinaciones léxicas que sean de nuestro interés.

3 Véase un punto de partida en Martos Eliche y Contreras Izquierdo (2018).

4 Para una introducción a la enseñanza de lengua formulaica, véase Rufat (2017). 
Volviendo a los verbos frecuentes, para su tratamiento la combinación léxica clave es la colocación; en concreto, la colocación entendida en sentido restringido. La tradición anglosajona extiende el concepto a cualquier combinación frecuente, con independencia de las relaciones lingüísticas que se establezcan entre sus miembros. Sin embargo, si aceptamos que todo objeto de estudio de la Lingüística ha de referirse a un concepto propiamente lingüístico, el criterio de la coocurrencia frecuente resulta insuficiente para establecer la existencia de una colocación, pues no es posible dar un contenido conceptual homogéneo al variado grupo de fenómenos que comparten tal criterio (seguimos a Bosque [2001] para establecer el concepto de colocación que manejamos, y que puede encontrarse ampliado en Sánchez Rufat, 2010). Por el contrario, entendemos que en la colocación entran en juego las propiedades combinatorias de las palabras; es decir, estas combinaciones son producto del carácter restrictivo del sistema lingüístico. Los predicados - los verbos, en este caso- seleccionan sus argumentos restringiendo el conjunto de piezas léxicas que pueden denotar de acuerdo con sus rasgos semánticos, por lo que las unidades seleccionadas no suelen ser piezas aisladas, sino clases léxicas.

Las restricciones que los predicados imponen a sus argumentos pueden ser de dos tipos: extralingüísticas e intralingüísticas. Las extralingüísticas están fundamentadas únicamente en nociones de naturaleza física (Bosque, 2005), con lo que podemos construir el paradigma extensional de acuerdo con el conocimiento que tenemos del mundo. Así, un verbo como lavar selecciona como argumentos sustantivos en función de complemento directo. Si atendemos a la restricción de naturaleza extralingüística de esta predicación, obtenemos una gran cantidad de argumentos que podemos reunir en dos clases léxicas de gran extensión: una formada por todos aquellos objetos materiales susceptibles de ser lavados (los platos, el coche, el jersey) y otra clase constituida por todos los seres animados susceptibles también de ser lavados (mi perro, mi bermano, Carlos). Una vez que conocemos el significado del predicado, podemos añadir piezas léxicas a ambas clases por sentido común y sin dificultad.

Por el contrario, si la restricción no está basada únicamente en nociones físicas, debe recurrirse al conocimiento del idioma para obtener las piezas léxicas que conforman la extensión; estamos, entonces, ante restricciones sistemáticas intralingüísticas o colocaciones en sentido restringido. En este caso, la restricción viene dada en función de las propiedades del predicado, ya sea este un adverbio, un adjetivo, un verbo, una preposición o un sustantivo. No basta el conocimiento del mundo, sino que es preciso un conocimiento profundo del 
predicado para obtener su paradigma extensional. Tomemos un verbo como ablandarse, que selecciona como argumentos sustantivos que designan materias u objetos sólidos; este paradigma extensional es muy amplio, pero puede construirse aplicando el sentido común, que nos remitirá a cualquier objeto que pueda ser ablandado. Sin embargo, cuando el verbo adopta su sentido figurado, próximo a moderarse, se combina con sustantivos pertenecientes a diferentes clases léxicas que, a priori, no podemos señalar: sustantivos que designan ciertas cualidades, facultades y sentimientos humanos, a menudo en referencias metonímicas, como corazón, voluntad o espíritu; sustantivos que denotan actitud o toma de posición frente a algo o alguien, o con otros que designan algunas formas organizadas de esas intenciones y creencias, como posición, postura o actitud; etc. Estas restricciones combinatorias de base semántica, características de los usos figurados de muchos verbos frecuentes, no se obtienen de las situaciones observadas en la realidad, como ocurre con las del paradigma conformado por sustantivos que designan materias, sino del análisis léxico, esto es, de las propiedades del predicado. Este paradigma extensional no tiene por qué coincidir en otras lenguas, pese a que no resulta complicado percibir los usos figurados del verbo como proyecciones naturales de los usos literales o físicos. De hecho, es razonable pensar que todos los usos de un verbo frecuente de una lengua, incluso aquellos en los que funciona como verbo de apoyo, comparten rasgos semánticos (Rufat, 2019).

La semántica cognitiva aporta una explicación de esta variedad de significados compartidos a partir del modelo de Lakoff y Johnson (1999)' Con un verbo como dar (Sánchez Rufat, 2015; Rufat, 2019), por ejemplo, podemos conceptualizar fragmentos específicos de la realidad bien directamente o bien a través de proyecciones metafóricas, pues en este verbo confluyen dos tipos de modelos cognitivos. El primero, más básico, se construye por medio de una estructura «preconceptual» a partir de imágenes que constantemente aparecen en nuestra experiencia física cotidiana. Este modelo se corresponde con el Esquema de Imagen del CAMINO (Lakoff y Johnson, 1999: 33), una experiencia física que tiene que ver con dominios básicos -en este caso, el espacio-. El CAMINO surge de nuestra percepción de entidades que se mueven a lo largo de un trayecto en el que hay un punto inicial, una meta y un recorrido: ir de un sitio a otro, lanzar una pelota o dar un lápiz a un niño tienen en común que hay una entidad X que está en un lugar de origen, se desplaza siguiendo una trayectoria y alcanza una meta. Por lo tanto, la idea de dar algo (entendiendo

5 Cheikh-Khamis Cases (2013) se apoya en estos planteamientos cognitivos para elaborar su propuesta de enseñanza de las colocaciones. 
por algo cualquier sustantivo que designa una entidad material) a alguien está en nuestra experiencia física cotidiana, por lo que a través de este modelo conceptualizamos de manera directa recurriendo únicamente a las categorías perceptivas. En este modelo se fundamentarían las restricciones sistemáticas extralingüísticas anteriormente mencionadas.

El segundo modelo, más complejo, se forma mediante proyecciones metafóricas que toman como dominio de origen las estructuras preconceptuales -esas categorías básicas e imágenes esquemáticas que provienen del dominio físico- y que permiten conformar un dominio abstracto, que es lo que se quiere conceptualizar (de ahí que hablemos de estructuras preconceptuales, previas a la conceptualización abstracta). Este modelo permite ampliar el conocimiento del mundo a partir de lo conocido, es decir, facilita la tarea de comprender aspectos complejos de la realidad en función de otros más básicos y más familiares. De este modo, el Esquema de Imagen del CAMINO, que se encuentra en un dominio del espacio físico, se proyecta hacia una estructura del «espacio conceptual», pues, una vez asumida la estructura del esquema origen-camino-destino, puede derivarse a casos abstractos y producirse así metáforas conceptuales como, en el caso del verbo dar, las siguientes: 1) A da [hacer llegar, proporcionar] un consejo, permiso, una orden, un ejemplo, una explicación (a C); 2 ) A da [hacer efectivo, ejecutar] un abrazo, un salto, un golpe, una clase, una respuesta (a C);3) A da [suscitar] miedo, tristeza, sed, felicidad, asco (a C), donde A suele ser un sujeto (SUJ) no agentivo; o sin posibilidad alguna de agente: darle a $\mathrm{C}$ [suscitar(se) en C] impresión, sensación. Por lo tanto, el modelo de Esquema de Imagen caracteriza la estructura, y los modelos metafóricos, las proyecciones que parten del modelo estructural. El enlace entre la cognición y la experiencia está, en consecuencia, motivado, y en esta motivación se fundamentan las restricciones sistemáticas intralingüísticas o colocaciones originadas a partir de los modelos que se corresponden con una estructura de esquema de imágenes.

Este planteamiento puede completarse con la propuesta de Ruhl (1989), quien defiende que las palabras polisémicas, entre las que se situarían los verbos frecuentes, se traten como una misma palabra. Distingue, para ello, entre un significado inberente o sistémico subyacente compartido por toda la gama de significados (literal y figurados) con la que esa palabra se usa, y una serie de rasgos intensionales activados por el contexto que corresponderían al significado inferido a partir de ese contexto. Dicho de otro modo, este tipo de palabra actualiza, a partir de su significado sistémico, una acepción - un significado, ya sea el básico o uno metafórico- en el discurso en función de las piezas léxicas 
que la acompañan. Así, la acepción que se actualiza en dar un abrazo, clase o un salto no es la misma que en dar cariño, alojamiento o confianza: mientras que en los primeros ejemplos el sentido es el de «ejecutar», en los últimos se refiere a «proporcionar», aunque los dos son significados figurados entendidos como proyecciones naturales del significado básico (el de dar en dar un lápiz). Como se deduce de todo lo anterior, esta diferencia significativa radica en la estructura interna del significado de una palabra, conformada por una serie de rasgos menores abstractos que intervienen en una gran variedad de conexiones significativas con otras palabras; los rasgos que se activan en una combinación no se activan en otra. Sabemos, por tanto, que el sistema nos permite sustituir dar en dar consejo por ofrecer, y eso se explica porque tanto dar como ofrecer comparten ciertos rasgos semánticos contenidos también en el significado de consejo, lo que determina su selección léxica. Lo mismo sucede con dar e impartir, que son intercambiables cuando seleccionan clase o curso; sin embargo, no se puede *impartir un consejo porque en este contexto los rasgos que comparte dar con consejo no los contiene impartir.

Bosque (2005: CXLII) aborda este asunto a través del concepto de concordancia léxica, considerándolo un rasgo distintivo de la combinatoria léxica: «las relaciones de concordancia constituyen la textura que permite hacer explícitas las conexiones que la sintaxis exige». De Miguel lo aplica a las construcciones con verbo de apoyo (2008 y 2011) y aprovecha, asimismo, el concepto de redundancia (propuesto también por Bosque, 2005), al que se refiere como

exponente de un fenómeno general de concordancia de rasgos léxicos, que se manifiesta en español en otros muchos procesos, y que consiste en la homogeneidad o la homogeneización de ciertas partículas del significado interno de las palabras que acaban proporcionando información redundante (De Miguel, 2008: 567).

Al respecto, Sanromán Vilas, a través de lo que denomina bipótesis de la compatibilidad semántica, manifiesta lo siguiente:

los VA [verbos de apoyo] se relacionan con el nombre con el que forman una CVA [construcción con verbo de apoyo] y con el verbo pleno correspondiente en virtud de algún vínculo semántico, esto es, algún componente semántico, presente en el verbo pleno, que se repite, total o parcialmente, en el VA y en el nombre (2014: 188). 
Por lo tanto, la redundancia, interpretada como una exigencia del sistema lingüístico, es una forma de concordancia de rasgos léxicos que está presente en la combinatoria léxica, aunque no siempre se produce (Bosque, 2005: CXLII). De este modo, la selección léxica de clases semánticas por parte del verbo frecuente en sus usos figurados -ya sea como verbo pleno o como verbo de apoyo- es un exponente del fenómeno de concordancia de rasgos que implica redundancia. Ello supone que el significado de una palabra puede descomponerse en rasgos menores, y las relaciones que se dan entre los significados de las palabras tienen que ver con el hecho de que comparten algunos de estos rasgos. De este modo, en las colocaciones de los verbos frecuentes se comparten ciertos rasgos semánticos contenidos en el significado del predicado (el verbo) y del argumento (sustantivos con los que coaparece), lo que determina la selección léxica que lleva a cabo el primero sobre el segundo.

Este concepto de colocación es el que tratamos de aplicar a la enseñanza de los verbos frecuentes del español, pues supone una aproximación muy rigurosa a todos los usos de un mismo verbo, incluyendo los usos como verbo de apoyo. Se trata, en definitiva, de agrupar todas las combinaciones -o gran parte de ellas- en clases léxicas para que el estudiante, en lugar de tener que aprender y memorizar innumerables combinaciones aisladas, pueda reducirlas a una serie manejable de conjuntos. Además, conocer la motivación lingüística que subyace a estas coapariciones, tanto la relativa a las metáforas o metonimias como la propiamente lingüística que fundamenta las restricciones léxicas, contribuye a su comprensión y fijación, ya que aumenta significativamente la facilidad con la que se pueden recordar; cuando una expresión está lingüísticamente motivada, la selección de palabras que la conforma es, en parte, explicable en términos de influencias identificables (Boers y Lindstromberg, 2009). Vemos una muestra a continuación.

\section{Enseñanza de los verbos frecuentes}

Utilizaremos como ejemplo el verbo tomar, que Tsutahara, mediante un índice que obtiene dividiendo el porcentaje del significado más frecuente entre el número total de significados, considera «el más difícil [del español] por tener abundantes sentidos y usos (10 tipos) y por el hecho de que sus frecuencias estén bien equilibradas» (2018: 371). Obsérvense algunas de las combinaciones de este verbo con sustantivos: tomar (las) riendas, tomar café, tomar (una) muestra, tomar (un) rumbo, tomar (un) aspecto, tomar fuerza, tomar cariño, tomar iniciativa, tomar (un) cariz, tomar distancia, tomar vitaminas, tomar medida(s), 
tomar impulso, tomar (un) camino, tomar (una) postura, tomar (una) decisión, tomar confianza, tomar nombre, tomar nota, tomar (una) dirección, tomar carne, tomar altura, tomar consistencia, tomar el mando, tomar declaración, tomar ventaja, tomar conciencia, tomar (una) determinación, tomar represalia(s), tomar (una) imagen, etc. Se trata tan solo de una muestra - existen muchas más combinaciones de este tipo-, pero suficiente para ilustrar la gran variedad semántica que existe entre los sustantivos que se combinan con el verbo. Para el aprendiente, esta versatilidad tiene dos problemas: primero, la dificultad de tener que ir aprendiendo cada una de las combinaciones posibles para cada uno de los verbos frecuentes - para los casos de dar, poner, hacer, etc. el panorama no es más alentador $^{6}-$; y segundo, muchos de estos verbos, como indicábamos antes, varían en las distintas lenguas. Un anglófono, por ejemplo, no dirá tomar, sino bave o drink a coffee, make a decision, etc.

Como decíamos, una manera de simplificar el proceso y de reconducirlo hacia un aprendizaje eficaz consiste, siempre que sea posible, en agrupar en clases léxicas todos los elementos con los que se combina un mismo verbo frecuente. Para que dicha agrupación sea rentable, ha de observarse el concepto de colocación que explicábamos en el apartado anterior, y que implica un vínculo semántico sólido, por un lado, entre todos los elementos de una clase entre sí, y por otro, entre todos esos elementos y el verbo, en virtud de la concordancia léxica mencionada (Bosque, 2005: CXLII). Estos vínculos semánticos refuerzan el carácter intralingüístico de la combinación, y son la clave para agrupar los elementos con los que se combina el verbo. Así, si tomamos los sustantivos de la relación anterior, podemos clasificarlos en las siguientes clases léxicas seleccionadas por tomar: a) sustantivos que designan líquidos, alimentos o remedios (café, carne, vitaminas); b) sustantivos que denotan energía, intensidad, relevancia (fuerza, impulso, altura); c) sustantivos que se refieren a propiedades físicas figuradas (aspecto, cariz, consistencia); d) sustantivos que designan acción de ejercer el mando (riendas, mando); e) sustantivos que denotan dirección física o figuradamente (rumbo, camino); etc. Cada una de estas combinaciones entre verbo y clase léxica serían colocaciones en sentido restringido, según las hemos definido. De entrada, resultará más rentable y razonable para un aprendiente trabajar con ellas que con las combinaciones del verbo y los sustantivos aisladamente.

Los repertorios más fiables de colocaciones en sentido restringido los ofrecen los diccionarios combinatorios Redes (2005) y Práctico (2006), coordinados por

6 Véanse los trabajos citados al final del apartado 2. 
Ignacio Bosque. En Redes aparecen las clases léxicas definidas al modo en que lo acabamos de hacer -de hecho, están tomadas de él-; en Práctico, los elementos se agrupan también en clases, pero no se definen, puesto que es un diccionario pensado fundamentalmente para el estudiante. Redes, sin embargo, constituye quizá la mejor herramienta de la que dispone el profesor para preparar actividades basadas en este planteamiento. El inconveniente es que, de los 50 verbos más frecuentes del español, solo se ofrecen las clases léxicas de 7 (dar, seguir, llevar, tomar, sentir, perder, entrar). En el resto de los casos, es el profesor el que debe clasificar la combinatoria en clases, bien recurriendo a estudios monográficos como los citados aquí -lo ideal, desde luego, sería que todos los verbos contaran con uno- o bien explorando la combinatoria por cuenta propia, para lo cual puede utilizar las combinaciones frecuentes sin clasificar que sí recogen los diccionarios en todos los casos o analizar corpus informatizados; insistimos en que solo será posible establecer clases léxicas si existe un vínculo semántico común para la serie.

Establecidas las clases léxicas, es momento de determinar un camino viable para su explotación didáctica a partir de los principios proporcionados por los enfoques léxicos. Una vez que se ha decidido con qué verbos y con qué combinaciones trabajar, es preciso atender a las fases de adquisición del vocabulario (establecidas metodológicamente en Rufat y Jiménez Calderón, 2017, y en Rufat, 2017). En primer lugar, algunas combinaciones pertenecientes a las colocaciones que se hayan seleccionado deben aparecer contextualizadas en el input para que el estudiante tenga la oportunidad de advertirlas y formular hipótesis sobre su significado y su uso; para contribuir a ello, pueden proponerse actividades cuya realización dependa de la comprensión del vocabulario nuevo. Tras este apercibimiento de las formas nuevas y su significado, se procede, en segundo lugar, a la internalización y el traslado a la memoria a largo plazo. El conocimiento se refuerza si se dan oportunidades repetidas de procesamiento profundo con la provisión de las mismas combinaciones, de modo que, mediante actividades muy pautadas y diseñadas expresamente, el alumno explore, practique y sistematice su forma, su significado y su uso. Se trata, en definitiva, de trabajar las colocaciones explícitamente. Proponemos, por ejemplo, que, a partir de combinaciones como tomar un zumo, tomar un taxi o tomar el sol, se pregunte al estudiante si conoce otros nombres con los que el verbo se combina, por si puede establecer relaciones a priori. Luego, se pide al estudiante que acuda a Práctico y localice la serie donde aparecen, respectivamente, zumo, taxi y sol; y que, a continuación, se pregunte qué tienen en común los elementos de cada una de esas series. Se dará cuenta, entonces, de 
que la primera serie se refiere a cosas que pueden ingerirse, y dentro de estas, distinguirá entre bebidas, comidas y medicamentos; la segunda, a medios de transporte; y la tercera, a elementos cuyos efectos pueden recibirse. Así, será el propio estudiante el que elabore las clases léxicas mediante un procesamiento profundo, que debería reflejar después en asociogramas (como se muestra en Higueras, 2007, o en Sánchez Rufat y Jiménez Calderón, 2013) o en mapas conceptuales que ayuden a fijar la combinatoria (como también proponen Baralo, 2006, o Moncó Taracena, 2013), en los que puede tratar de añadir nuevas unidades a cada una de las series. En el ejemplo propuesto, las colocaciones identificadas de tomar podrían verterse en un mapa de este tipo:

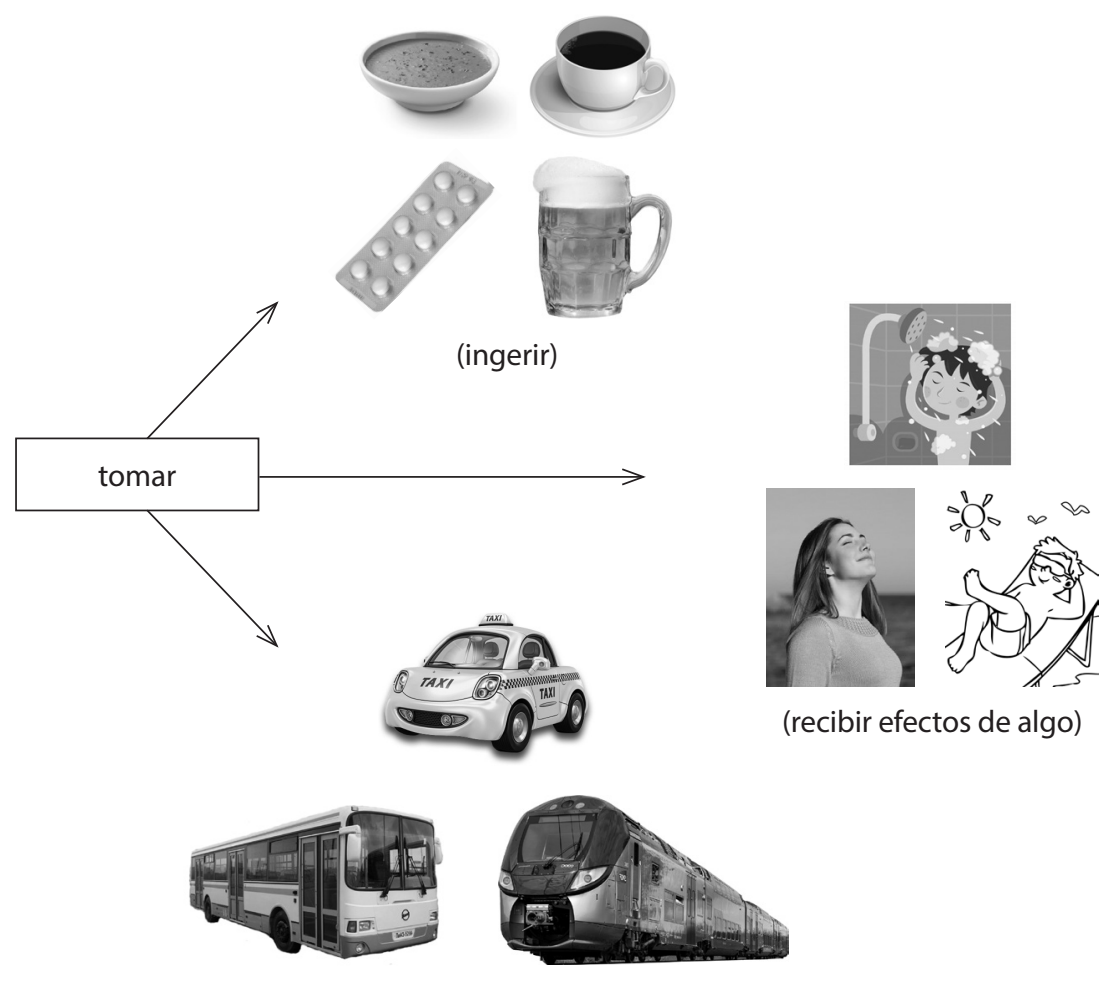

(utilizar vehículos de recorrido regular)

Figura 1. Mapa conceptual a partir de algunas combinaciones de tomar

Conviene, a continuación, que el estudiante se plantee cómo se expresan esos conceptos en su propia lengua, compruebe en qué casos se utiliza el verbo equivalente en la $\mathrm{L}_{1} \mathrm{y}$, en los casos en los que no, identifique el verbo que 
selecciona al sustantivo. A partir de ahí, puede ahondarse tanto como sea preciso -y siempre que se cuente con herramientas para ello- en otras relaciones lingüísticas paradigmáticas o sintagmáticas para contribuir a la formación de redes léxicas. Por ejemplo, si se trabaja con dar, se puede advertir, directamente o guiando al estudiante para que lo observe en contexto, que este verbo suele formar un par adyacente con pedir cuando se combina con nombres de comunicación: dar/pedir + información, consejo, explicación, respuesta, etc. (Sanromán Vilas, 2014: 203); o que ponerse es incompatible con adjetivos que se combinen únicamente con ser y no con estar (Conde Noguerol, 2018a: 52).

Para terminar, puede plantearse la conveniencia de ahondar en el aula sobre la naturaleza semántica de estos verbos a partir de sus combinaciones o de sus diferentes comportamientos léxico-sintácticos. Al fin y al cabo, ambos aspectos -semántico y combinatorio- son caras de la misma moneda, pues, como apunta De Miguel (2011: 40), es en la sintaxis donde verdaderamente se visualiza la estructura léxica. Convendría, entonces, realizar la exploración semántica de manera paralela a la exploración sintáctica. Parece claro que la mera traducción del verbo a la $\mathrm{L}_{1}$ no es suficiente por las razones ya expuestas: si un anglófono descodifica tomar como take, tal vez produzca * tomar una siesta o *tomar una reverencia, al calcar del inglés las estructuras take a nap y take a vow, respectivamente. Si aceptamos, en consonancia con los planteamientos de la semántica cognitiva expuestos más arriba y con varios de los trabajos ya citados, que existen vínculos semánticos entre todos los usos del verbo, pueden llevarse al aula consideraciones encaminadas a que el estudiante los establezca al tiempo que determina las clases léxicas seleccionadas por el verbo. En esa línea, podrían aprovecharse estudios que van todavía más allá y proponen significados inherentes o sistémicos de algunos de estos verbos, como los de Sánchez Rufat (2015: 209), en el que se afirma que el de dar sería «(A) causa que B pase de no existir a existir (en C, de manera que los seres $\mathrm{C}$ disfruten o padezcan B), pudiendo ser B un lápiz, un salto o cariño»; o el de Sanromán Vilas (2014), que define bacer como «a. 'X hace $\mathrm{Y}$ ' - b. 'X causa que $\mathrm{Y}$ exista'». No se trata, obviamente, de trasladar directamente al aula explicaciones tan abstractas, pero sí puede buscarse que el estudiante tome conciencia del rasgo semántico compartido. Tsutahara (2018: 370) propone, por ejemplo, que sean los estudiantes quienes agrupen los distintos usos de un verbo atendiendo al significado del verbo en cada uso, lo cual desembocaría en la determinación del rasgo semántico que el verbo comparte con cada serie de argumentos y en una apreciación del significado general del predicado. Y también, siempre sobre la base de que los distintos 
usos del verbo participan de rasgos semánticos comunes, pueden plantearse actividades que relacionen los usos literales y figurados del verbo, de manera que el estudiante observe que, en realidad, ambos están comprendidos en el mismo significado (más precisiones en Romero, 2008: 189-192). A partir de un uso literal, el estudiante puede rastrear usos figurados en Práctico, realizar un asociograma y elaborar la información léxica que le permitirá establecer la conexión semántica y producir nuevas combinaciones7.

\section{Conclusiones}

Los verbos frecuentes son unidades léxicas especialmente relevantes y complejas para los estudiantes de español, lo que justifica el diseño de vías específicas para su enseñanza. Así, partiendo de que sus múltiples combinaciones pueden agruparse en clases léxicas definidas y relacionadas semánticamente entre sí y con el verbo, proponemos el siguiente procedimiento: 1) seleccionar, de entre el repertorio proporcionado, los verbos con los que se quiere trabajar en función del nivel de los estudiantes, necesidades, rentabilidad, etc.; 2) no deben trabajarse ni todos los verbos ni todas las combinaciones de un verbo al mismo tiempo, sino distribuir los contenidos de manera razonable, o sea, seleccionar las colocaciones con las que se quiere trabajar a partir de los diccionarios combinatorios, de un trabajo teórico sobre el verbo o, si no existe otra posibilidad y siempre que resulte viable, mediante análisis de corpus; 3 ) buscar o elaborar input donde aparezcan las colocaciones escogidas y proponer actividades para que sea el estudiante el que elabore semánticamente las clases léxicas seleccionadas por el verbo a través de asociogramas y mapas conceptuales, y permitir que el estudiante contraste sus hipótesis; 4) aportar consideraciones semánticas que favorezcan el establecimiento de los vínculos entre los distintos usos del verbo y justifiquen la lógica de su significado; 5) proporcionar posibilidades de recuperación y producción de las colocaciones trabajadas, tanto de manera guiada para fijar la combinación como de forma abierta (comunicativa); 6) ocuparse más adelante de nuevas clases léxicas seleccionadas por el verbo, para que el estudiante vaya completando su combinatoria (prescindir, en cualquier caso, de las combinaciones que no se consideren relevantes).

El camino trazado responde estrictamente a principios de los enfoques léxicos respaldados rigurosamente por la investigación: enseñanza del vocabulario más frecuente, observación de las fases de adquisición del vocabulario, elaboración semántica, establecimiento de relaciones con la L1, relevancia de

7 Véase un ejemplo, aunque a partir de corpus, en Sánchez Rufat y Jiménez Calderón (2013). 
la combinatoria léxica y fortalecimiento de redes. Téngase en cuenta, en cualquier caso, que existe aún un gran déficit de estudios sobre estos verbos, los cuales serán imprescindibles para desarrollar aplicaciones didácticas sólidas y para constatar que, obviamente, no todos los verbos podrán ser tratados del mismo modo.

\section{Bibliografía}

Alderson, J. C. (2005): Diagnosing Foreign Language Proficiency. Londres: Continuum.

Baralo, M. (2006): «Cómo crear redes entre palabras en el aula de ELE». III Encuentro Práctico de Profesores de ELE: https://www.encuentro practico. com/pdfwo6/baralo.pdf (05-07-2019).

Blanco Escoda, X. (2000): «Verbos soporte y clase de predicados en español». LEA: Linguiística española actual, 22(1), 99-118.

Barcroft, J. (2012): «Semantic and Structural Elaboration in L2 Lexical Acquisition». Language Learning, 52, 323-363.

Boers, F., Lindstromberg, S. (2009): Optimizing a Lexical Approach to Instructed Second Language Acquisition. Basingstoke: Palgrave Macmillan.

Boers, F., Stengers, H. (2008): «A Quantitative Comparison of the English and Spanish Repertories of Figurative Idioms». En: Frank Boers, Seth Lindstromberg (eds.), Cognitive Linguistic Approaches to Teaching Vocabulary and Phraseology. Berlín, Nueva York: Mouton De Gruyter, 355-374.

Bosque, I. (2001): «Sobre el concepto de colocación y sus límites». Lingüística española actual, 23(1), 8-35.

Bosque, I. (2005): «Combinatoria y significación. Algunas reflexiones». En: Ignacio Bosque (dir.), Redes. Diccionario combinatorio del español contemporáneo. Madrid: SM, LXXVII-CLXXIV.

Bosque, I. (2005): Redes. Diccionario combinatorio del español contemporáneo. Madrid: SM.

Bosque, I. (2006): Práctico. Diccionario combinatorio del español contemporáneo. Madrid: SM.

Cheikh-Khamis Cases, F. (2013): Lingüistica cognitiva aplicada a la enseñanza del léxico en segundas lenguas. Las colocaciones en clase de ELE. Trabajo de fin de máster. Madrid: Universidad Nacional de Educación a Distancia. 
Cheikh-Khamis Cases, F. (2016): «Las construcciones de hacerse y volverse con adjetivos y sustantivos metonímicos en ELE». $X$ Congreso Internacional AELCO: https://www.researchgate.net/profile/Fatima_Cheikh Khamis/ publication/310620851_2016_Las_construcciones_de_hacerse_y_volv rse_ con_adjetivos_y_sustantivos_metonimicos_en_ELE/links/5834213a08ae10 fo737d828/2016-Las-construcciones-de-hacerse-y-volverse-con-adjetivos-y sustantivos-metonimicos-en-ELE.pdf?origin=publication_detail (05-07-2019).

Conde Noguerol, M. E. (2018a): «Contribución al estudio léxico-semántico del verbo ponerse». Pragmalingüistica, 26, 33-53.

Conde Noguerol, M. E. (2018b): «La expresión del cambio de estado: delimitación léxico-semántica del verbo hacer en la construcción hacerse + adjetivo/sustantivo con sujetos animados». Anuario de Letras. Lingüistica y Filología, VI, 5-34.

Consejo de Europa (2002): Marco común europeo de referencia para las lenguas: aprendizaje, enseñanza y evaluación. Madrid: Ministerio de Educación, Cultura y Deporte, Anaya.

Davies, M., Davies, K. H. (2018): A Frequency Dictionary of Spanish. Core Vocabulary for Learners. Abingdon/Nueva York: Routledge.

De Miguel, E. (2008): «Construcciones con verbo de apoyo en español. De cómo entran los nombres en la órbita de los verbos». Actas del XXXVII Simposio Internacional de la Sociedad Española de Lingüistica: http://www. unav.es/linguis/simposiosel/actas/ (05-07-2019).

De Miguel, E. (2011): «En qué consiste ser verbo de apoyo». En: María Victoria Escandell Vidal et. al. (eds.), 6o problemas de gramática. Madrid: Akal, 139146.

Erman, B., Warren, B. (2000): «The Idiom Principle and the Open-Choice Principle». Text, 20, 87-120.

Gumiel Molina, S. (2008): «Sobre las diferencias entre ser y estar. El tipo de predicado y el tipo de sujeto». RedELE, 13, 16-19.

Higueras, M. (2007): «Técnicas para la enseñanza del léxico». Mosaico, 20, 37-42.

Housen, A. (2002): «A Corpus-Based Study of the L2-Acquisition of the English Verb System». En: Seth Granger et al. (eds.), Computer Corpora, Second Language Acquisition and Foreign Language Teaching. Amsterdam: John Benjamins, 77-116.

Lakoff, G., Johnson, M. (1999): Philosopby in the Flesh: The Embodied Mind and Its Challenge to Western Thought. Nueva York: Basic Books. 
Leow, R. P. (2015): Explicit Learning in the L2 Classroom: A Student-Centered Approach. Abingdon/Nueva York: Routledge.

Lewis, M. (1993): The Lexical Approach: The State of ELT and a Way Forward. Hove: Language Teaching Publications.

Lewis, M. (1997): Implementing the Lexical Approach: Putting Theory into Practi$c e$. Hove: Language Teaching Publications.

Lewis, M. (2000): Teaching Collocation: Further Developments in the Lexical Approach. Hove: Language Teaching Publications.

Martos Eliche, F., Contreras Izquierdo, N. (2018): «El empleo de corpus para el aprendizaje de secuencias formulaicas en ELE/EL2. La frecuencia de uso en el nivel $\mathrm{B}_{2}$ del PCIC». CHIMERA. Romance Corpora and Linguistic Studies, 5 (1), 1-26.

Moncó Taracena, S. (2013): «Adquisición de las construcciones con el verbo hacer, enfoque plurilingüe». Revista Nebrija de Lingüística Aplicada a la Enseñanza de Lenguas, 13: https://www.nebrija.com/revista-linguistica/ adquisicion-de-las construcciones-con-el-verbo-hacer-enfoque-plurilingue.html (05-07-2019).

Nagini, P. (2008): «The Mental Lexicon». Journal of the Indian Academy of Applied Psychology, 34(1), 181-186.

Nation, I. S. P. (2001): Teacbing and Learning Vocabulary. New York: Newbury House.

Nation, I. S. P. (2008): Teaching Vocabulary. Strategies and Techniques. Boston: Heinle.

Richards, J. C. (1976): «The role of vocabulary teaching». TESOL Quarterly, 10(1), 77-89.

Romero, J. (2008): «Selección semántica y selección categorial en el diccionario Redes». Anuario de estudios filológicos, 31, 177-194.

Rufat, A. (2017): «Estrategias para la enseñanza de secuencias formulaicas en el aula de español como lengua extranjera». En: Dimitrinka Níkleva (ed.), Necesidades y tendencias en la formación del profesorado de español como lengua extranjera. Berna: Peter Lang, 257-282.

Rufat, A. (2019): La investigación de corpus de aprendientes basada en el análisis contrastivo de la interlengua: el caso de dar. Jaén: UJA Editorial.

Rufat, A., Jiménez Calderón, F. (2017): «Aplicaciones de enfoques léxicos a la enseñanza comunicativa». En: Francisco Herrera (ed.), Enseñar léxico en el aula de español. El poder de las palabras. Barcelona: Difusión, 47-56. 
Rufat, A., Jiménez Calderón, F. (2019): «Vocabulario». En: Javier MuñozBasols, Elisa Gironzetti, Manel Lacorte (eds.), The Routledge Handbook of Spanish Language Teaching: metodologías, contextos y recursos para la enseñanza del español L2. Abingdon/Nueva York: Routledge, 229-242.

Ruhl, C. (1989): On Monosemy: A Study on Linguistic Semantics. Albany: State University of New York Press.

Sánchez Rufat, A. (2010): «Apuntes sobre las combinaciones léxicas y el concepto de colocación». Anuario de estudios filológicos, 33, 291-306.

Sánchez Rufat, A. (2015): «La naturaleza léxico-semántica del verbo dar en la construcción verbo + nombre». Anuario de estudios filológicos, 38, 205-223.

Sánchez Rufat, A., Jiménez Calderón, F. (2013): «Combinatoria léxica y corpus como input». Language Design, 14, 61-81.

Sánchez Rufat, A., Jiménez Calderón, F. (2015): New perspectives on acquisition and teaching of Spanish vocabulary / Nuevas perspectivas sobre la adquisición y la enseñanza del vocabulario del español. Número monográfico de Journal of Spanish Language Teaching, 2 (2).

Sanromán Vilas, B. (2014): «La alternancia dar / hacer en construcciones con verbo de apoyo y nombre de comunicación». Borealis. An International Journal of Spanish Linguistics, 3 (2), 185-222.

Stengers, H. (2009): The Idiom Principle Put to the Test: An Exercise in Applied Comparative Linguistics. Tesis doctoral. Bruselas: Vrije Universiteit Brussel.

Swan, M. (1997): «The Influence of the Mother Tongue on Second Language Vocabulary Acquisition and Use». En: Norbert Schmitt, Michael McCarthy (eds.), Vocabulary: Description, Acquisition and Pedagogy. Cambridge: Cambridge University Press, 162-180.

Tomasello, M. (2003): Constructing a Language: A Usage-Based Theory of Language Acquisition. Cambridge (MA), Harvard University Press.

Tsutahara, R. (2018): «Una clase sobre los usos de los verbos habituales basada en un índice marcador de la dificultad de aprendizaje». Foro de Profesores de E/ LE, 365-374: https://ojs.uv.es/index.php/foroele/article/view/13362/12242 (05-07 2019).

Urbaniak, E. (2016): «El análisis pragmalingüístico de las palabras baúl: el caso del verbo bacer». Linred, 14: https://ebuah.uah.es/dspace/bitstream/handle/10017/30259/ analisis_urbaniak_R_2016_14.pdf? sequence $=1$ \&isAllowed $=y$ (05-07-2019).

Wray, A. (2002): Formulaic Language and the Lexicon. Cambridge: Cambridge University Press. 
Francisco Jiménez Calderón and Anna Rufat

University of Extremadura

\section{The teaching of frequent verbs through lexical approaches}

Keywords: frequent verbs, light verbs, lexical approaches, collocations, vocabulary teaching

Since the first works on lexical approaches appeared, research has firmly supported the principles which they are based on in language teaching. This has also been the case in Spanish Language Teaching, although the integration of these principles in the text books is still rather limited; in fact, few approaches have been developed to tackle specific or problematic aspects of such methods. Considering all this, this paper presents a proposal based on the implementation of certain precepts of the lexical approaches to the teaching of frequent verbs in Spanish, which, far from being safe linguistic elements, constitute a very important source of errors for the learners because of their semantic breadth and wide co-occurrence in very varied lexical-syntactic contexts. From a methodological point of view, the proposal is based on the following points: 1) frequency as a criterion for the selection of vocabulary; 2) gradual vocabulary learning; 3 ) lexical co-occurrence as a key aspect of vocabulary and discourse; 4) collocation as a concept understood in a restricted sense, based on linguistic notions; 5) $\mathrm{L}_{1}$ as an essential filter; 6) strengthening of lexical networks to fix the combinatorial relations; and, finally and with the same purpose, 7) deep processing by learners. It will be shown that the resulting procedure contributes decisively to the teaching-learning process by taking advantage of the combinatorial capacity of these verbs based on the selection of lexical classes. 
Francisco Jiménez Calderón in Anna Rufat

Univerza v Extremaduri

\section{Leksikalni pristopi k poučevanju pogostih glagolov}

Ključne besede: pogosti glagoli, podporni glagoli, leksikalni pristopi, kolokacije, poučevanje besedišča

Že od prvih del na temo leksikalnih pristopov raziskave zanesljivo potrjujejo pomen njihovih načel pri poučevanju jezikov. Enako velja tudi za španščino, čeprav je vključevanje teh načel v učna gradiva še počasno. S konkretnimi ali težavnimi vidiki pristopa se namreč spoprijema malo metod, zato se v prispevku predlaga neposredno uporabo določenih vodil leksikalnih pristopov pri poučevanju pogostih glagolov v španskem jeziku. Ti še zdaleč niso varne jezikovne prvine, temveč so zaradi svojih pomenskih razsežnosti in pojavljanja v zelo raznolikih leksikalno-skladenjskih kontekstih pri učencih izredno pomemben vir napak. Metodološko se predlog opira na naslednje točke: 1) pogostost kot merilo za izbiro besedišča; 2) postopno učenje besedišča; 3) sopojavljanje besed kot ključni vidik besedišča in diskurza; 4) koncept kolokacije v ožjem smislu, osnovan na jezikovnih pojmih; 5) vloga prvega jezika kot nepogrešljivega filtra; 6) krepitev leksikalnih mrež in 7) globoko procesiranje s strani učencev, oba kot sredstvi za utrjevanje sopojavljalnih zvez. $\mathrm{V}$ prispevku se pokaže, da končni postopek odločilno pripomore k procesu poučevanja-učenja, saj na podlagi izbire leksikalnih razredov izkorišča sopojavljalne zmožnosti teh glagolov. 